\title{
Fluorimetric nitrite analysis using 2,3-diaminonaphthalene: an improvement of the method
}

\author{
M.-C. Carré, B. Mahieuxe, J.-C. André, M.-L. Viriot* \\ DCPR-GRAPP - UMR 7630 CNRS-INPL, Groupe ENSIC, 1, rue Grandville, 54000 Nancy, France
}

\begin{abstract}
One of the fluorimetric methods for nitrite determination is based on the reaction of nitrite ions with 2,3-diaminonaphthalene (DAN) to form fluorescent $1-[\mathrm{H}]$-naphthotriazole. The procedure is sensitive, simple and rapid. However, the DAN reagent is carcinogenic and its use in a large excess for the reaction might be a drawback for an extensive application. In particular to know if a stoechiometric quantity of the reagent might be sufficient to run the reaction, the method was re-examined. In fact, using the latter condition, it was still possible to get nitrite determination in the range 0 to $50 \mu \mathrm{g} \mathrm{NO}_{2}^{-} \cdot \mathrm{L}^{-1}$, with a rather smaller analysis time.
\end{abstract}

Keywords. Nitrite - Fluorescence - 2,3-diaminonaphthalene.

\section{Introduction}

With the objective to get new analytical methods for the determination of oxygen in sea water [1] and/or pollutants in the environment water (nitrate, nitrite, etc.) [2], we developed technologies based on fluorimetry with the use of optical fibers. Fluorimetric methods were selected for their great sensitivity and also for their possible remote measurement. Concerning the nitrate determination, the generally required drastic conditions (in the major cases highly acidic media [3]), led us to study an indirect method of nitrate analysis, i.e. reduction to nitrite [see reference 4 for a review].

Among the described methods for the nitrite determination, the one using 2,3-diaminonaphthalene (DAN) was chosen (Fig. 1). The method based on the reaction of nitrite with DAN (slightly fluorescent) which affords 1-[H]-naphthotriazole (highly fluorescent) was first described by Wiersma [5] and later improved by others [6-10] and more particularly by Damiani and Burini [11].

The major drawback of the method is the use in a large excess of the reagent DAN, which is a carcinogenic compound. Indeed, in the procedure described by Damiani and Burini, DAN was used exceedingly large if compared to the nitrite concentration to be determined: for the maximal nitrite concentration of $50 \mu \mathrm{g} \mathrm{NO}_{2}^{-} \cdot \mathrm{L}^{-1}$, DAN remaining in solution represented approximatively 60 times the quantity involved in the stoechiometric reaction. In order to diminish the required DAN quantity, it would be of interest to study if a stoechiometric reaction between DAN and nitrite might be still feasible. It is the purpose of the present paper, in which an improvement of the procedure is described.<smiles>Nc1cc2ccccc2cc1N</smiles>

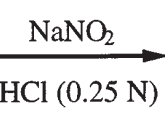

2,3-diaminonaphthalene (DAN)<smiles>c1ccc2cc3[nH]nnc3cc2c1</smiles>

1-[H]-naphthotriazole
Fig. 1. Reaction between nitrite ions and 2,3-diaminonaphthalene in $0.25 \mathrm{~N} \mathrm{HCl}$.

\section{Experimental section}

\section{Reagents}

Sodium nitrite (99\%) was from Merck (D - Darmstadt) and dried at $100{ }^{\circ} \mathrm{C}$ before using. 2,3-diaminonaphthalene (97\%) was from Aldrich (St Quentin Fallavier, France). $37 \%$ minimum chlorhydric acid (R.P. Normapur ${ }^{\mathrm{TM}}$ ) was from Prolabo (Paris, France) and sodium hydroxide (puriss p.a. > $98 \%$ ) from Fluka (St Quentin Fallavier, France). The water used was demineralized.

\section{Apparatus}

Fluorescence measurements were made with a SPEX 1681 Fluorolog spectrofluorimeter equipped with a continuousspectrum Xenon lamp source (450 watt). The excitation wavelength was set at $365 \mathrm{~nm}$ and the emission was measured at $405 \mathrm{~nm}$. The fluorescence intensities are only

\footnotetext{
* Correspondence and reprints
}

Received June 8, 1999; revised October 1, 1999; accepted October 5, 1999. 


\section{Original articles}

corrected for the basic fluorescence emission of the solution without DAN and nitrite.

\section{Procedure}

Nitrite solution at $100 \mathrm{mg} \mathrm{NO} \mathrm{NO}_{2}^{-} \cdot \mathrm{L}^{-1}$ (N.1) was prepared by dissolving $15 \mathrm{mg}$ of sodium nitrite in $100 \mathrm{~mL}$ of demineralized water. Nitrite solutions at $50 \mu \mathrm{g} \mathrm{NO}_{2}^{-} \cdot \mathrm{L}^{-1}$ (N.2) and $5 \mu \mathrm{g} \mathrm{NO} 2^{-} \cdot \mathrm{L}^{-1}$ (N.3) was prepared respectively from (N.1) with a 2000 dilution factor and (N.2) with a 10 dilution factor in demineralized water. Sets of $10 \mathrm{~mL}$ volume of standard solutions containing respectively 0 to $50 \mu \mathrm{g} \mathrm{NO}{ }_{2}^{-} \cdot \mathrm{L}^{-1}$ and 0 to $5 \mu \mathrm{g} \mathrm{NO}_{2}^{-} \cdot \mathrm{L}^{-1}$ were prepared by pipetting suitable volumes of respectively the (N.2) and (N.3) solutions and completed with demineralized water.

2,3-Diaminonaphthalene (DAN) (10 mg) was dissolved in $100 \mathrm{~mL}$ of $0.25 \mathrm{~N}$ hydrochloric acid to obtain the stock solution of DAN at $100 \mathrm{mg} . \mathrm{L}^{-1}$. Sets of $50 \mathrm{~mL}$ volume of standard DAN solutions at respectively $0.2 ; 1 ; 2$ and $10 \mathrm{mg} . \mathrm{L}^{-1}$ were prepared by pipetting suitable volumes of the DAN solution at $100 \mathrm{mg} . \mathrm{L}^{-1}$ and completed with $0.25 \mathrm{~N}$ $\mathrm{HCl}$.

Nitrite analyses were conducted by adding $0.5 \mathrm{~mL}$ of DAN solutions to $5 \mathrm{~mL}$ of nitrite ones. The mixture was hand shaked then let stand for $10 \mathrm{~min}$. Then $0.25 \mathrm{~mL}$ of a $0.58 \mathrm{M}$ sodium hydroxide solution was added (final volume for the fluorescence analysis of $5.75 \mathrm{~mL}$ ), the mixture was homogenized and the fluorescence measurement was immediately done.
For experiments with time, at time zero, $10 \mathrm{~mL}$ of a DAN solution was added to $100 \mathrm{~mL}$ of a nitrite solution, then the mixture was stirred for $2 \mathrm{~min}$ and let stand. Over the analysis period, samplings of $5.5 \mathrm{~mL}$ were added to $0.25 \mathrm{~mL}$ of $0.58 \mathrm{M} \mathrm{NaOH}$ (final volume for the fluorescence analysis of $5.75 \mathrm{~mL}$ ). The solution was hand shaked for homogenizing and immediately analyzed by fluorimetry.

\section{Results and discussion}

\section{Effect of DAN concentration on the nitrite determination sensitivity}

Five sets of experiments were performed by using a DAN concentration from 100 to $0.2 \mathrm{mg} . \mathrm{L}^{-1}$ and by keeping for each set nitrite samples at concentrations of respectively 0 , $10,20,30,40,50 \mu \mathrm{g} \mathrm{NO}{ }_{2}^{-} \cdot \mathrm{L}^{-1}$. Tables I and II gathered the nitrite and DAN quantities respectively used and figure 2 shows the fluorescence responses relative to each DAN and $\mathrm{NO}_{2}^{-}$couple. With the aim to determine the limits of the detectable nitrite concentration, two additional sets of experiments were done (figures relative to the results not shown). First, by taking a DAN concentration of $1 \mathrm{mg} . \mathrm{L}^{-1}$ and nitrite in the range 0 to $25 \mu \mathrm{g} \mathrm{NO}{ }_{2}^{-} \cdot \mathrm{L}^{-1}$, the analysis was still feasible since a good calibration curve was obtained in this range. Second by using a lower DAN concentration of $0.2 \mathrm{mg} . \mathrm{L}^{-1}$ and nitrite in the range 0 to $5 \mu \mathrm{g} \mathrm{NO}{ }_{2}^{-} \cdot \mathrm{L}^{-1}$, the limit of the analysis was reached, since no correlation was found between the nitrite concentration and the fluorescence intensity measured.

Table I. $\mathrm{NO}_{2}{ }^{-}$concentrations (see figure 2; samples issued from the (N.2) solution).

\begin{tabular}{|c|c|c|}
\hline $\begin{array}{l}\text { Initial nitrite quantities } \\
\qquad\left(\mu \mathrm{g} \mathrm{NO} 2_{2}^{-} \cdot L^{-1}\right)\end{array}$ & $\begin{array}{l}\text { Initial molar nitrite concentrations } \\
\qquad\left(\mathrm{mol} \mathrm{NO}_{2}^{-} \cdot L^{-1}\right)\end{array}$ & $\begin{array}{l}\text { Molar nitrite concentrations in the mixture } \\
\text { for the fluorescence measurement } \\
\text { Dilution factor: } 1.15 \\
\left(\text { mol } \mathrm{NO}_{2}^{-} \cdot L^{-1}\right)\end{array}$ \\
\hline 0 & 0 & 0 \\
\hline 10 & $2.210^{-7}$ & $1.910^{-7}$ \\
\hline 20 & $4.310^{-7}$ & $3.810^{-7}$ \\
\hline 30 & $6.510^{-7}$ & $5.710^{-7}$ \\
\hline 40 & $8.710^{-7}$ & $7.610^{-7}$ \\
\hline 50 & $1.110^{-6}$ & $9.510^{-7}$ \\
\hline
\end{tabular}

Table II. DAN concentrations tested for nitrite determination (see figure 2).

\begin{tabular}{|c|c|c|}
\hline $\begin{array}{c}\text { Initial DAN quantities } \\
\left(m g . L^{-1}\right)\end{array}$ & $\begin{array}{l}\text { Initial molar DAN concentrations } \\
\left(\mathrm{mol}^{\mathrm{L}} \mathrm{L}^{-1}\right)\end{array}$ & $\begin{array}{c}\text { Molar DAN concentrations in the mixture } \\
\text { for the fluorescence measurement } \\
\text { Dilution factor: } 11.5 \\
\left(\text { mol. } L^{-1}\right)\end{array}$ \\
\hline 0.2 & $1.310^{-6}$ & $1.110^{-7}$ \\
\hline 1 & $6.310^{-6}$ & $5.510^{-7}$ \\
\hline 2 & $1.310^{-5}$ & $1.110^{-6}$ \\
\hline 10 & $6.310^{-5}$ & $5.510^{-6}$ \\
\hline 100 & $6.310^{-4}$ & $5.510^{-5}$ \\
\hline
\end{tabular}




\section{Original articles}

In order to discuss the present results, especially in regard to the relative quantity of DAN which reacts with nitrite ions, the stoechiometric molar ratio in the final analysis volume was searched for each set of DAN concentration and the corresponding line is reported on figure 3. Taking into account the highest nitrite concentration used of $50 \mu \mathrm{g} \mathrm{NO}{ }_{2}^{-} \cdot \mathrm{L}^{-1}$, the values for DAN at 10 and $100 \mathrm{mg} . \mathrm{L}^{-1}$ respectively were not reported, because DAN was always in large excess for the corresponding experiments. For the DAN concentration of $2 \mathrm{mg} . \mathrm{L}^{-1}$, DAN was still in excess for the nitrite in the range 0 to $50 \mu \mathrm{g} \mathrm{NO}{ }_{2}^{-} \cdot \mathrm{L}^{-1}$, as well as for the sets of DAN at $1 \mathrm{mg} \cdot \mathrm{L}^{-1}$ and nitrite in the range 0 to $25 \mu \mathrm{g} \mathrm{NO}{ }_{2}^{-} \cdot \mathrm{L}^{-1}$ and DAN at $0.2 \mathrm{mg} . \mathrm{L}^{-1}$ and nitrite in the range 0 to $5 \mu \mathrm{g} \mathrm{NO}{ }_{2}^{-} \cdot \mathrm{L}^{-1}$. Of course, for the sets of DAN at respectively 1 and $0.2 \mathrm{mg} . \mathrm{L}^{-1}$, the DAN concentrations were in lack for nitrite concentrations above the respective values of the stoechiometric line. In order to know if the analysis would be still feasible with a lack of DAN, the influence of the time of the reaction was studied (see further).

\section{Effect of the reaction time on the fluorescence intensity}

With a constant nitrite concentration, independently of the DAN concentration until stoechiometric one, an identical final fluorescence intensity must be expected for a sufficient reaction time. On the contrary, if the DAN concentration is lower than the stoechiometric one, this would not be observed. To confirm this hypothesis, the influence of the reaction time was studied.

First, the reaction was conducted for a sample of $50 \mu \mathrm{g}$ $\mathrm{NO}_{2}^{-} \cdot \mathrm{L}^{-1}$ (9.5 $10^{-7} \mathrm{~mol} \mathrm{NO}_{2}^{-} \cdot \mathrm{L}^{-1}$ in the final volume) in acidic media in function of different DAN concentrations. Samplings analysis on time was conducted until the fluorescence intensity reached a final plateau value (Fig. 4). The reaction was complete in the first 5 minutes for a DAN concentration of $100 \mathrm{mg} . \mathrm{L}^{-1}\left(5.510^{-5} \mathrm{~mol} . \mathrm{L}^{-1}\right.$ in the final volume) and the maximal fluorescence intensity remained constant with time. For a DAN concentration of $10 \mathrm{mg} . \mathrm{L}^{-1}$ (5.5 $10^{-6}$ mol.L $\mathrm{L}^{-1}$ in the final volume), the reaction was complete only after 40 minutes, the maximum intensity also remained constant after this time and reached the preceding value. With the lower DAN concentration of $2 \mathrm{mg} . \mathrm{L}^{-1}$, the fluorescence intensity progressively increased and for an enough long time, it would reach the preceding value because DAN is still in excess in comparison to the nitrite concentration (the observation time was too short to reach it). On the contrary, the DAN concentration of $1 \mathrm{mg} . \mathrm{L}^{-1}$ was in lack in comparison to the nitrite (see Fig. 3), then the fluorescence intensity progressively increased but would not reach the previous value. Nevertheless, by considering the fluorescence responses over a short period of time $(<30$ min), it appeared that the value of $1 \mathrm{mg} . \mathrm{L}^{-1}$ of DAN might still agree for nitrite analysis.

In fact, the set of experiments reported in figure 5 corresponds to the study of the influence of the reaction time for a constant DAN concentration of $1 \mathrm{mg} . \mathrm{L}^{-1}$ with nitrite concentrations ranging from 10 to $50 \mu \mathrm{g} \quad \mathrm{NO}_{2}^{-} \cdot \mathrm{L}^{-1}$.

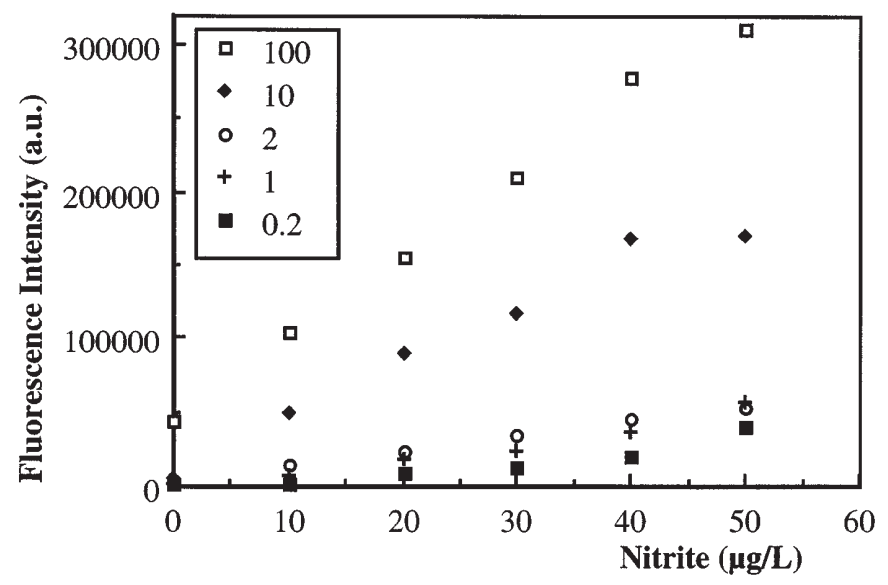

Fig. 2. Fluorescence intensity in function of $\mathrm{NO}_{2}{ }^{-}$concentrations at different DAN concentrations (see the values enclosed in $\mathrm{mg} . \mathrm{L}^{-1}$ ), for a reaction time of $10 \mathrm{~min}$.

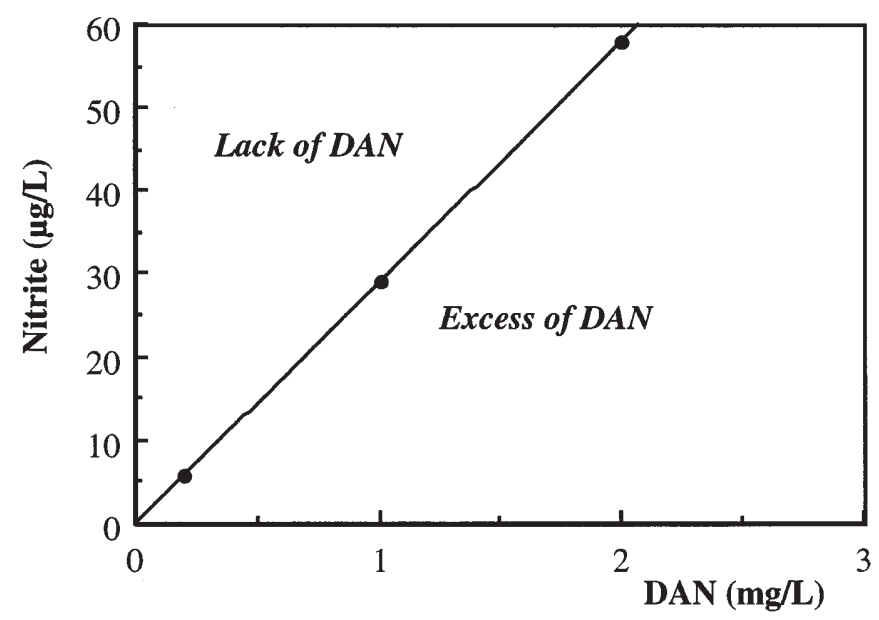

Fig. 3. Representation of the stoechiometric line for the reaction between $\mathrm{NO}_{2}^{-}$and DAN (stoechiometric molar ratio in the final analysis volume).

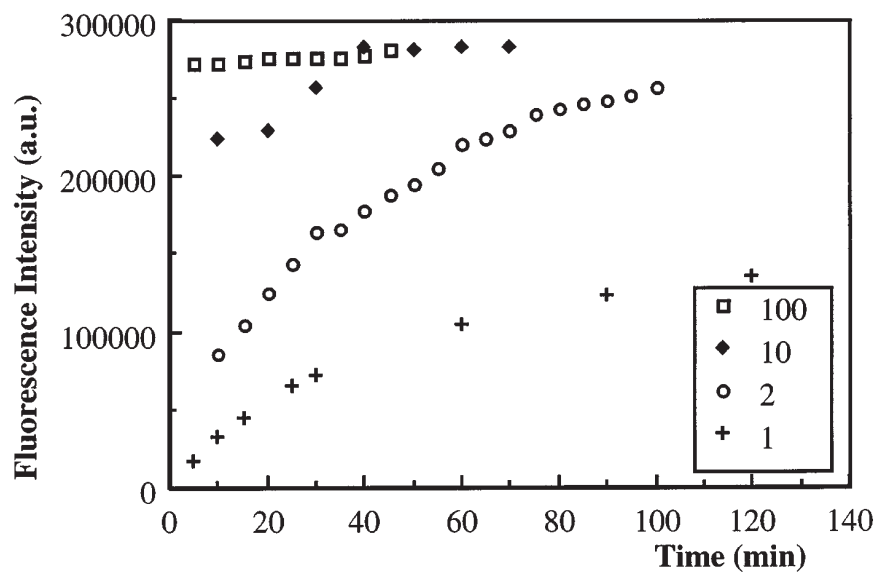

Fig. 4. Fluorescence intensity with the reaction time for different DAN concentrations (see the values enclosed in mg. $\mathrm{L}^{-1}$ ) with $\mathrm{NO}_{2}{ }^{-}$ concentration at $50 \mu \mathrm{g} \mathrm{NO}{ }_{2}^{-} \cdot \mathrm{L}^{-1}$. 


\section{Original articles}

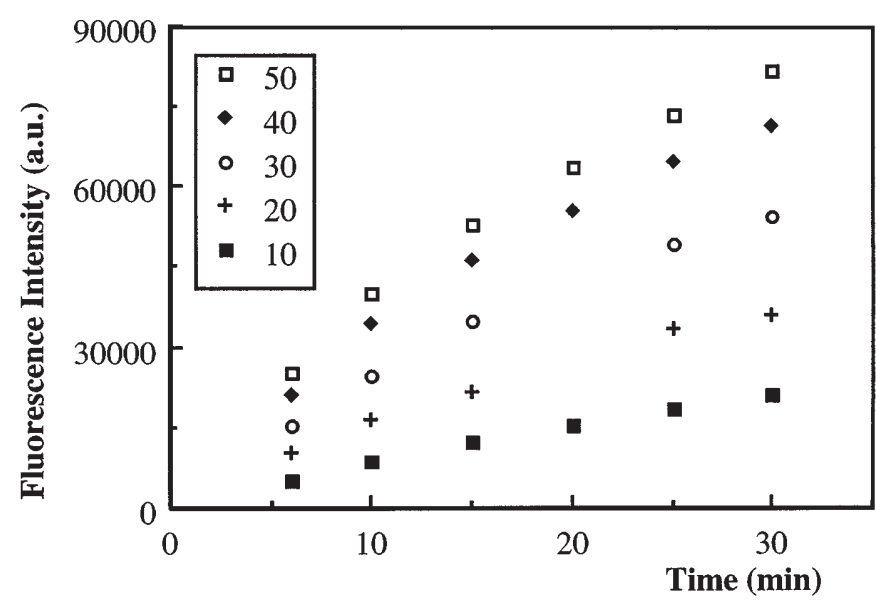

Fig 5. Fluorescence intensity with the reaction time for different nitrite concentrations (see the values enclosed in $\mu \mathrm{g} \mathrm{NO}{ }_{2}^{-} \cdot \mathrm{L}^{-1}$ ) at a DAN concentration of $1 \mathrm{mg} . \mathrm{L}^{-1}$.

The fluorescence responses were very convincing. By taking in consideration a fixed time of sampling, fluorescence intensities correlated well with nitrite concentrations. Very interestingly, measurements with a good precision can be done after only 6 minutes of reaction.

\section{Conclusion}

The procedure for the determination of nitrite with 2,3diaminonaphthalene (DAN) was considerably improved, mainly by reducing the DAN reagent required for nitrite analysis (going from 100 to $1 \mathrm{mg} . \mathrm{L}^{-1}$ of DAN) without affecting analysis time. Indeed, the method analysis remains very fast, since a 6 minutes reaction time is sufficient to allow nitrite analysis in the range 0 to $50 \mu \mathrm{g} \mathrm{NO}{ }_{2}^{-} \cdot \mathrm{L}^{-1}$.

\section{Acknowledgements}

The authors thank M. Ismariny and K. Richard for their participation to the experimental work. MENRT is acknowledged for its financial support as well as CNRS and INSERM (M.-C. Carré).

\section{References}

1. Gouin, J.-F.; Baros, F.; Birot, D.; André, J.-C. Entropie 1995, 84, 192.

2. Mahieuxe, B.; Carré, M.-C.; Viriot, M.-L.; André, J.-C.; Donner, M. J. Fluoresc. 1994, 4, 7.

3. Axelrod, H.-D.; Bonelli, J.-E.; Lodge Jr, J.-P. Anal. Chim. Acta 1970, 51, 21.

4. Viriot, M.-L.; Mahieuxe, B.; Carré, M.-C.; André, J.-C. Analusis 1995, 23, 312.

5. Wiersma, J.H. Anal. Lett. 1970, 3, 123.

6. Sawicki, C.R. Anal. Lett. 1971, 4, 761.

7. Wheeler, G.L.; Lott, P.F. Microchem. J. 1974, 19, 390.

8. Gladilovich, D.B.; Grigor'ev, N.N.; Sedik, K.; Pozdnyakova, N.E. Zh. Anal. Khim. 1989, 44, 1388 (CA: 111-180372q).

9. Grigor'ev, N.N.; Gladilovich, D.B.; Sedik, K. Vestn. Leningr. Univ. Ser. 4: Fiz. Khim. 1990, 1, 112 (CA: 113-34057r).

10. Mukai, Y.; Hara, H.; Taniguchi, H. Bunseki Kagaku 1991, 40, 105 (CA: 115-104945w).

11. Damiani, P.; Burini, G. Talanta 1986, 33, 649. 